\title{
Idiopathic intracranial hypertension and bariatric surgery: a systematic review
}

\author{
Warren Y. L. Sun, MD \\ Noah J. Switzer, MD, MPH \\ Jerry T. Dang, MD \\ Richdeep Gill, MD, PhD \\ Xinzhe Shi, MPH, MMSc \\ Christopher de Gara, MBBS \\ Daniel Birch, MSc, MD \\ Andrew Nataraj, MD \\ Shahzeer Karmali, MD, MPH
}

Accepted July 24, 2019

\section{Correspondence to:}

J.T. Dang

Walter C. Mackenzie Health Sciences

Centre

8440 - 112 St NW

Edmonton AB T6G 2B7

dang2@ualberta.ca

DOI: $10.1503 /$ cjs.016616

\begin{abstract}
Background: Idiopathic intracranial hypertension (IIH) is a rare condition typically affecting women with obesity who are of child-bearing age. Patients commonly present with headaches, visual disturbances, pulsatile tinnitus and papilledema. The association between IIH and obesity has been well established in the literature, suggesting that weight loss may contribute to improving IIH. For patients with severe obesity for whom conservative management is not successful, bariatric surgery is an effective modality for weight loss. We aimed to systematically review the literature to determine the efficacy of bariatric surgery in the treatment of IIH
\end{abstract}

Methods: We conducted a comprehensive search of MEDLINE, Embase, Scopus, the Cochrane Library and Web of Science (limited to studies in humans published in English between January 1946 and July 2015).

Results: Twelve primary studies ( $n=39$ patients) were included in the systematic review. All patients had a preoperative diagnosis of IIH. Preoperative body mass index (BMI) was $47.4 \pm 3.6 \mathrm{~kg} / \mathrm{m}^{2}$; BMI improved to $33.7 \pm 2.1 \mathrm{~kg} / \mathrm{m}^{2}$ and $33.9 \pm 11.6 \mathrm{~kg} / \mathrm{m}^{2}$ at 6 and 12 months postoperatively, respectively. Lumbar puncture opening pressures decreased from $34.4 \pm 6.9 \mathrm{~cm} \mathrm{H}_{2} \mathrm{O}$ to $14.0 \pm 3.6 \mathrm{~cm} \mathrm{H}_{2} \mathrm{O}$ after surgery. Common symptoms of IIH improved after bariatric surgery: headaches (100\% preoperatively v. $10 \%$ postoperatively), visual complaints $(62 \%$ v. $44 \%)$, tinnitus $(56 \%$ v. $3 \%)$ and papilledema ( $62 \%$ v. $8 \%)$.

Conclusion: Bariatric surgery appears to lead to considerable improvement in IIH. Idiopathic intracranial hypertension is not a well-publicized comorbidity of obesity, but its presence may be considered as an indication for bariatric surgery.

Contexte : L'hypertension intracrânienne (HTIC) idiopathique est une affection rare qui touche surtout les femmes atteintes d'obésité en âge de procréer. Les symptômes courants sont des maux de tête, des troubles de la vue, des acouphènes pulsatiles et un œdème papillaire. Le lien entre l'HTIC idiopathique et l'obésité est bien établi dans la littérature, ce qui suggère que la perte de poids pourrait améliorer le tableau clinique de l'HTIC. Pour les patients atteints d'obésité sévère pour lesquels le traitement conservateur ne fonctionne pas, la chirurgie bariatrique est un moyen efficace de perdre du poids. Cette revue systématique de la littérature vise à déterminer l'efficacité de la chirurgie bariatrique dans le traitement de l'HTIC idiopathique.

Méthodes : Nous avons interrogé MEDLINE, Embase, Scopus, la Bibliothèque Cochrane et Web of Science (limites : études portant sur les humains publiées en anglais entre janvier 1946 et juillet 2015).

Résultats : Douze études primaires ( $n=39$ patients) ont été incluses dans la revue systématique. Tous les patients avaient un diagnostic préopératoire d'HTIC idiopathique. L'indice de masse corporelle (IMC) préopératoire était de 47,4 $\pm 3,6 \mathrm{~kg} / \mathrm{m}^{2}$; l'IMC est passé à $33,7 \pm 2,1 \mathrm{~kg} / \mathrm{m}^{2} 6$ mois après l'opération, puis à $33,9 \pm 11,6 \mathrm{~kg} / \mathrm{m}^{2} 12$ mois après l'opération. Les pressions d'ouverture des ponctions lombaires sont passées de $34,4 \pm 6,9 \mathrm{~cm} \mathrm{H}_{2} \mathrm{O}$ à $14,0 \pm 3,6 \mathrm{~cm} \mathrm{H}_{2} \mathrm{O}$ après l'opération. Les symptômes courants de l'HTIC idiopathique se sont améliorés après la chirurgie bariatrique : maux de tête (100\% avant opération c. $10 \%$ après), troubles de la vue $(62 \%$ c. $44 \%)$, acouphènes pulsatiles (56\% c. $3 \%)$ et œedème papillaire ( $62 \%$ c. $8 \%$ ).

Conclusion : La chirurgie bariatrique semble améliorer considérablement les symptômes d'HTIC idiopathique. Cette affection n'est pas une comorbidité bien connue de l'obésité, mais sa présence peut être une indication pour la chirurgie bariatrique comme traitement. 
I diopathic intracranial hypertension (IIH), also commonly referred to as pseudotumour cerebri, is a rare condition typically affecting women with obesity who are of child-bearing age. ${ }^{1}$ Patients with IIH commonly present with headaches, visual disturbances, pulsatile tinnitus, nausea, vomiting, photophobia and neck, shoulder or radicular pain., ${ }^{1,2}$ Patients with $\mathrm{IIH}$ can also present with visual field defects, visual acuity deficits, blind spot enlargement and papilledema on fundoscopy. ${ }^{1}$ Idiopathic intracranial hypertention is classically diagnosed using the modified Dandy criteria; ${ }^{3}$ however, it is commonly diagnosed in patients presenting with signs and symptoms associated with increased intracranial pressure, a lumbar puncture opening pressure greater than $25 \mathrm{~cm} \mathrm{H}_{2} \mathrm{O}$ and evidence of normal cerebral anatomy on imaging. ${ }^{4}$ Patients with IIH require urgent diagnosis and management to prevent further complications, as IIH can ultimately result in permanent loss of vision. ${ }^{1}$

The association between IIH and obesity has been well established in the literature. ${ }^{5-10}$ A common theory suggests that obesity causes increased intra-abdominal pressure resulting in increased pleural pressure and cardiac filling pressure. The increased pressures lead to increased venous pressure, decreased venous blood flow from the brain and, ultimately, increased intracranial pressure. ${ }^{8}$ Although both conservative management with diuretics ${ }^{11,12}$ and invasive interventions, such as therapeutic lumbar puncture, ${ }^{13}$ optic nerve sheath fenestration $^{14}$ and shunt surgery, ${ }^{15-17}$ are available, these options are not definitive treatments and provide only symptomatic relief for patients. ${ }^{1,2,9,10}$ Because the link between $\mathrm{IIH}$ and obesity has been well established, weight loss has the potential to improve IIIH symptoms. Where diet and exercise fail to result in significant weight loss, other methods need to be explored for the treatment of obesity and consequently $\mathrm{IIH}$.

As bariatric surgery remains the only treatment modality that has been proven to be successful for patients with severe obesity for whom conservative management has been unsuccessful, various case reports and case series have identified bariatric surgery as a potential option for patients with IIH..$^{8,18-31}$ We aimed to systematically review the literature to determine the efficacy of bariatric surgery for the treatment of IIH.

\section{Methods}

A comprehensive search of MEDLINE, Embase, Scopus, the Cochrane Library and Web of Science from 1946 to July 2015 was completed. Title searching was restricted to the following keywords and terms: bariatric surgery/ gastric bypass/gastric band/sleeve gastrectomy and intracranial hypertension/pseudotumour cerebri. Only studies in humans that were published in English were included.

All cohort studies, case series and case reports were included in this study. Abstracts were selected on the basis of the following inclusion criteria: patients diagnosed with
$\mathrm{IIH}$, patients who have undergone bariatric surgery, and studies directly comparing pre- and postoperative outcomes. The full-text articles for all selected abstracts were reviewed thoroughly using the same inclusion criteria by 2 independent reviewers (W.Y.L.S., N.J.S.). Pertinent data were extracted independently by 2 reviewers (W.Y.L.S., N.J.S.) from full-text articles, including the basic demographic characteristics of the patients, the number of patients with symptoms, lumbar puncture opening pressures and pre- and postoperative body mass index (BMI).

\section{Results}

Preliminary database searches of the literature yielded 120 articles with 115 potentially relevant articles after duplicates were removed. After titles and abstracts were screened, 33 eligible studies were retained. One additional record was identified through reference searching. Full-text articles were reviewed, and 12 primary studies comprising 39 participants were included in this systematic review (Fig. 1).

Twelve primary studies ${ }^{18-23,25-28,30,31}$ were included in the systematic review, accounting for a total of 39 participants, all of whom were diagnosed with IIH preoperatively. Of the 39 participants, 38 were female, and the average age of all participants was 32.5 years. The demographic characteristics of the patients in the primary studies are summarized in Table 1 . The quality of the primary studies was not evaluated as the available evidence was scarce and case reports had to be included.

Signs and symptoms associated with $\mathrm{IIH}$ were recorded for all 39 patients preoperatively (Table 2 and Table 3). All 39 patients (100\%) had headaches; 24 (62\%) had visual symptoms, which included blurring, visual disturbances or ocular pain; and $22(56 \%)$ had pulsatile tinnitus. Preoperative fundoscopy revealed that 24 patients (62\%) had papilledema and $22(56 \%)$ had visual field deficits. The mean preoperative lumbar puncture opening pressure was $34.4 \pm 6.9 \mathrm{~cm} \mathrm{H}_{2} \mathrm{O}$.

All patients underwent bariatric surgery. Twenty-nine (74\%) underwent Roux-en-Y gastric bypass, 6 (15\%) underwent adjustable gastric banding, 3 (8\%) underwent sleeve gastrectomy and $1(3 \%)$ had gastric exclusion surgery. Average preoperative $\mathrm{BMI}$ was $47.4 \pm 3.6 \mathrm{~kg} / \mathrm{m}^{2}$. Average $\mathrm{BMI}$ at 6 and 12 months postoperatively was $33.7 \pm 2.1 \mathrm{~kg} / \mathrm{m}^{2}$ and $33.9 \pm 11.6 \mathrm{~kg} / \mathrm{m}^{2}$, respectively (Table 3 ).

Postoperatively, 35 patients $(90 \%)$ reported significant improvement in or resolution of their headaches at followup, which varied from 3 months to 3 years (Table 2). Seven patients $(29 \%)$ reported improvement in or resolution of visual symptoms. All but 1 patient reported resolution of pulsatile tinnitus (96\%). Postoperative fundoscopy revealed that 21 patients $(88 \%)$ had resolved or stabilized papilledema and 4 patients (18\%) had resolved or stabilized visual field deficits. Postoperative lumbar punctures were recorded in only 4 patients, with the average opening pressure improving to $14.0 \pm 3.6 \mathrm{~cm} \mathrm{H}_{2} \mathrm{O}$ (Table 3). 


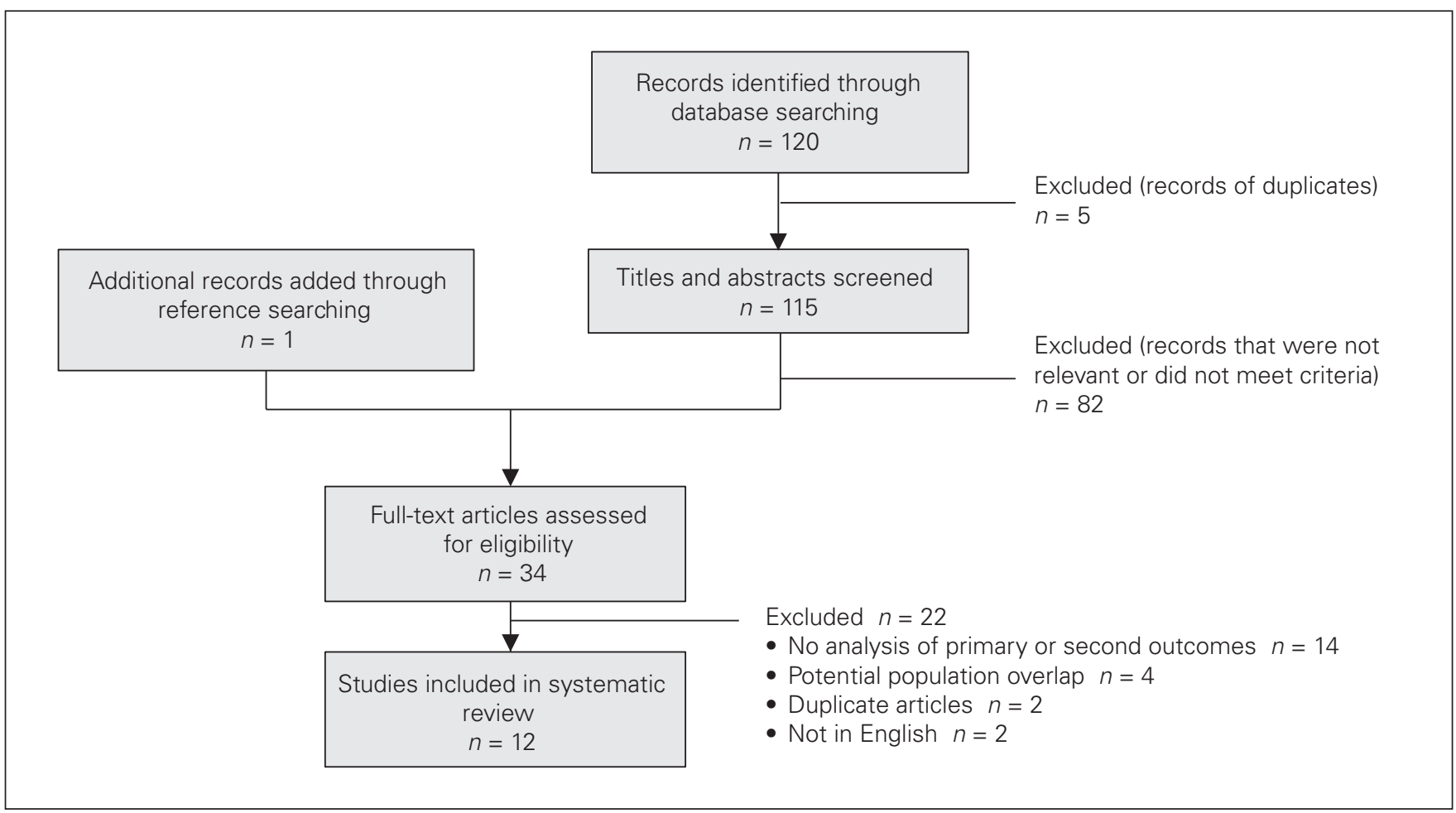

Fig. 1. Flow chart of study selection.

Table 1. Demographic characteristics of the 39 study participants

\begin{tabular}{|c|c|c|c|c|c|}
\hline Study & Design & Surgery type & No. of participants & No. of females & Age, mean, ${ }^{*} \mathrm{yr}$ \\
\hline Amaral et al. $1987^{18}$ & $\mathrm{CR}$ & GES & 1 & 1 & 24 \\
\hline Chandra et al. $2007^{19}$ & CR & LRYGB & 1 & 1 & 16 \\
\hline Egan et al. $2011^{20}$ & PC & LAGB & 4 & 4 & 32 \\
\hline Graber et al. $2010^{21}$ & $\mathrm{CR}$ & SG & 1 & 1 & 22 \\
\hline Leslie et al. $2008^{22}$ & CR & LRYGB & 1 & 0 & 12 \\
\hline Levin et al. $2015^{23}$ & $\mathrm{CR}$ & LRYGB & 1 & 1 & 29 \\
\hline Nadkarni et al. $2004^{25}$ & $\mathrm{CR}$ & RYGB, SG & 2 & 2 & 42 \\
\hline Noggle and Rodning $1986^{26}$ & $\mathrm{CR}$ & Revision RYGB & 1 & 1 & 34 \\
\hline Soto et al. $2005^{27}$ & $\mathrm{CR}$ & LRYGB & 1 & 1 & 30 \\
\hline Stangherlin et al. $2008^{28}$ & CR & LAGB & 1 & 1 & 47 \\
\hline Sugerman et al. $1999^{30}$ & $\mathrm{RC}$ & 23 RYGB, 1 LAGB & 24 & 24 & 34 \\
\hline Um et al. $2013^{31}$ & $\mathrm{CR}$ & SG & 1 & 1 & 26 \\
\hline \multicolumn{6}{|c|}{$\begin{array}{l}\mathrm{CR}=\text { case report; } \mathrm{GES}=\text { gastric exclusion surgery; } \mathrm{LAGB}=\text { laparoscopic adjustable gastric banding; } \mathrm{LRYGB}=\text { laparoscopic Roux-en-Y gastric bypass; } \mathrm{PC}=\text { prospective } \\
\text { cohort; } \mathrm{RC}=\text { retrospective cohort; RYGB = Roux-en-Y gastric bypass; } \mathrm{SG}=\text { sleeve gastrectomy. }\end{array}$} \\
\hline
\end{tabular}

\section{Discussion}

Our systematic review found that bariatric surgery is associated with complete remission or substantial improvement of signs and symptoms associated with IIH. Headaches, which are the most commonly reported symptom of $\mathrm{IIH}$ and were seen in all of the patients preoperatively, completely resolved or significantly improved in most of the patients $(89.7 \%)$. Similarly, $95.5 \%$ of patients with pulsatile tinnitus reported complete resolution of this symptom following bariatric surgery, and $87.5 \%$ of patients with papilledema found on perioperative fundoscopy experienced resolution, improvement or stabilization following surgery. The results from this study suggest a promising treatment option for IIH. The efficacy of established treatment modalities for IIH such as acetazolamide, optic nerve sheath fenestration and shunt surgery have been studied, ${ }^{32,33}$ but to our knowledge no direct comparison between bariatric surgery and other treatment modalities has been published in the literature. 
Table 2. Summary of major preoperative findings No. of patients with symptoms, $n=39$

\begin{tabular}{|c|c|c|c|c|c|c|c|}
\hline \multirow[b]{2}{*}{ Study } & \multicolumn{5}{|c|}{ No. of patients with symptoms, $n=39$} & \multirow[b]{2}{*}{$\begin{array}{l}\text { Mean LP OP, * } \\
\mathrm{cm} \mathrm{H}_{2} \mathrm{O}\end{array}$} & \multirow[b]{2}{*}{$\begin{array}{c}\text { Mean BMI, } † \\
\mathrm{~kg} / \mathrm{m}^{2}\end{array}$} \\
\hline & $\begin{array}{c}\text { Headaches } \\
n=39\end{array}$ & $\begin{array}{c}\text { Visual symptoms } \\
\qquad n=24\end{array}$ & $\begin{array}{l}\text { Pulsatile tinnitus } \\
\qquad n=22\end{array}$ & $\begin{array}{c}\text { Papilledema } \\
n=24\end{array}$ & $\begin{array}{l}\text { Visual field deficits } \\
\qquad n=22\end{array}$ & & \\
\hline Amaral et al. $1987^{18}$ & 1 & 1 & - & 1 & 1 & 33 & - \\
\hline Chandra et al. $2007^{19}$ & 1 & 1 & - & 1 & 1 & 50 & 42.3 \\
\hline Egan et al. $2011^{20}$ & 4 & 2 & - & 3 & 2 & - & 46.1 \\
\hline Graber et al. $2010^{21}$ & 1 & 1 & - & - & 1 & 55 & - \\
\hline Leslie et al. $2008^{22}$ & 1 & 1 & - & 1 & 1 & 55 & 48 \\
\hline Levin et al. $2015^{23}$ & 1 & 1 & - & 1 & 1 & 39 & 46.8 \\
\hline \multicolumn{8}{|l|}{ Nadkarni et al. $2004^{25}$} \\
\hline Patient 1 & 1 & 1 & - & 1 & 0 & 20 & 44.3 \\
\hline Patient 2 & 1 & 1 & - & 1 & - & - & 51.5 \\
\hline Noggle and Rodning $1986^{26}$ & 1 & 1 & - & 1 & 1 & - & - \\
\hline Soto et al. $2005^{27}$ & 1 & 1 & - & 1 & 1 & 37.7 & 44 \\
\hline Stangherlin et al. $2008^{28}$ & 1 & - & - & - & - & - & 48.5 \\
\hline Sugerman et al. $1999^{30}$ & 24 & 13 & 22 & 12 & 13 & 32.4 & 47 \\
\hline Um et al. $2013^{31}$ & 1 & - & - & 1 & - & - & 67 \\
\hline \multicolumn{8}{|c|}{$\begin{array}{l}\mathrm{BMI}=\text { body mass index; LP OP = lumbar puncture opening pressure. } \\
{ }^{\star} \mathrm{T} \text { The mean LP OP of participants across all included studies was } 34.6 \mathrm{~cm} \mathrm{H}_{2} \mathrm{O} \text {. } \\
\text { †The mean BMI of participants across all included studies was } 47.4 \text {. }\end{array}$} \\
\hline
\end{tabular}

Table 3. Summary of major postoperative findings

\begin{tabular}{|c|c|c|c|c|c|c|c|c|}
\hline \multirow[b]{2}{*}{ Study } & \multicolumn{5}{|c|}{ No. of patients with remission of, improvement in or stabilization of symptoms } & \multirow[b]{2}{*}{$\begin{array}{l}\text { Mean } \\
\mathrm{LP} \mathrm{OP}_{1}^{*} \\
\mathrm{~cm} \mathrm{H}_{2} \mathrm{O}\end{array}$} & \multicolumn{2}{|c|}{ Mean BMI, † kg/m² } \\
\hline & $\begin{array}{c}\text { Headaches } \\
n=35\end{array}$ & $\begin{array}{l}\text { Visual } \\
\text { symptoms } \\
n=7\end{array}$ & $\begin{array}{l}\text { Pulsatile tinnitus } \\
\qquad n=21\end{array}$ & $\begin{array}{c}\text { Papilledema } \\
n=21\end{array}$ & $\begin{array}{l}\text { Visual field deficits } \\
\qquad n=4\end{array}$ & & At 6 mo & At $12 \mathrm{mo}$ \\
\hline Amaral et al. $1987^{18}$ & 1 & 1 & - & 1 & 1 & 17 & - & - \\
\hline Chandra et al. $2007^{19}$ & 1 & - & - & 1 & 1 & 12 & 33 & - \\
\hline Egan et al. $2011^{20}$ & 4 & 2 & - & 3 & 1 & - & - & - \\
\hline Graber et al. $2010^{21}$ & 1 & - & - & - & - & 10 & - & - \\
\hline Leslie et al. $2008^{22}$ & - & - & - & 0 & 0 & - & 32 & 24 \\
\hline Levin et al. $2015^{23}$ & 1 & 1 & - & 0 & 0 & 17 & 36 & 35 \\
\hline \multicolumn{9}{|l|}{ Nadkarni et al. $2004^{25}$} \\
\hline Patient 1 & 1 & - & - & 1 & - & - & - & 23.4 \\
\hline Patient 2 & 1 & 1 & - & 1 & - & - & - & - \\
\hline Noggle and Rodning $1986^{26}$ & - & 1 & - & 1 & 0 & - & - & - \\
\hline Soto et al. $2005^{27}$ & 1 & 1 & - & - & 1 & - & - & - \\
\hline Stangherlin et al. $2008^{28}$ & - & - & - & - & - & - & - & 35.3 \\
\hline Sugerman et al. $1999^{30}$ & 23 & - & 21 & 12 & - & - & - & - \\
\hline Um et al. $2013^{31}$ & 1 & - & - & 1 & - & - & - & 52 \\
\hline \multicolumn{9}{|c|}{$\begin{array}{l}\mathrm{BMI}=\text { body mass index; } \mathrm{LP} \text { OP = lumbar puncture opening pressure. } \\
{ }^{*} \text { The mean LP OP of participants across all included studies was } 14.0 \mathrm{~cm} \mathrm{H}_{2} \mathrm{O} \text {. } \\
\text { †The mean BMI of participants across all included studies was } 33.7 \text { at } 6 \mathrm{mo} \text { and } 33.9 \text { at } 12 \mathrm{mo} \text {. }\end{array}$} \\
\hline
\end{tabular}

The cause of IIH is unknown, but several hypotheses exist. ${ }^{8,13,34-36}$ A theory linking obesity and $\mathrm{IIH}$ suggests that obesity raises intra-abdominal pressure, leading to increased pleural pressure and cardiac filling pressures, which in turn impedes venous return in the brain and ultimately results in increased intracranial pressure. ${ }^{8}$ Although the definitive cause of $\mathrm{IIH}$ has not been identified, obesity (through its effect on intra-abdominal pressure) is thought to be a significant contributing factor.

Several studies have demonstrated that weight loss is an effective treatment for IIH. ${ }^{37-39}$ Although the ideal treatment for obesity is lifestyle management, the effectiveness of diet and exercise for weight loss in patients with obesity is poor for several reasons, including the complex pathophysiology of obesity management. ${ }^{40-43}$ The emergence of bariatric surgery for the morbidly obese population has provided these patients with an effective way to lose a substantial amount of weight. ${ }^{44-46}$

The 2 most commonly performed bariatric procedures are laparoscopic Roux-en-Y gastric bypass and laparoscopic sleeve gastrectomy. Owing to the paucity of primary data on bariatric surgery as a treatment for $\mathrm{IIH}$, we elected to include all types of bariatric procedures in this study, including gastric banding. Several studies have alluded to 
the superiority of laparoscopic Roux-en-Y gastric bypass and laparoscopic sleeve gastrectomy over gastric banding because of the greater weight loss and lower rates of complications and revisions with the former procedures. ${ }^{44,47,48}$ Although our study suggests that bariatric surgery may be an effective treatment for IIH, we recommend laparoscopic Roux-en-Y gastric bypass or laparoscopic sleeve gastrectomy as the primary procedures of choice.

There is a lack of prospective studies on IIH that describe its natural history. Although most patients have a protracted course in which symptoms gradually worsen without treatment, ${ }^{49}$ there have also been cases of severe and rapidly progressive $\mathrm{IIH} .^{50}$ Although bariatric surgery is a sound treatment option for obesity and potentially $\mathrm{IIH}$, its effectiveness for $\mathrm{IIH}$ is observed when the patient loses weight and subsequently decreases their intra-abdominal pressure. For patients with more acute presentations of $\mathrm{IIH}$ and vision loss, emergent symptomatic relief must be provided in terms of neurosurgical $^{15-17}$ and ophthalmic techniques ${ }^{14}$ as suggested by Fridley and colleagues. ${ }^{9}$ Nonetheless, the improvement in symptoms following bariatric surgery suggests the potential for bariatric surgery to be useful in the treatment of $\mathrm{IIH}$.

With the increasing incidence of obesity worldwide and advances in surgical techniques, the demand for bariatric surgery is increasing. ${ }^{51}$ Many patients who are eligible for bariatric surgery are unable to receive it because of access and financial barriers. ${ }^{52}$ As a result, public health systems have to triage patients on the basis of the severity of their obesity and their obesity-related comorbidities. Although there is a strong association between IIH and obesity, IIH is not widely recognized as an indication for bariatric surgery. By improving access to bariatric surgery in patients who are obese and who have IIH, there is potential to target a group that has substantial potential for improvement. Therefore, further research, such as randomized controlled trials and cost-benefit analyses, should be performed not only to establish $\mathrm{IIH}$ as an indication for bariatric surgery, but also to compare the efficacy of bariatric surgery with that of the current standard of care for IIH.

Although other reviews on this topic have been published,, 910 to our knowledge this systematic review is the most recent and comprehensive. The conclusions and findings were, not surprisingly, similar across studies. We did not report on 3 additional studies that met our inclusion criteria but were included in the other reviews. ${ }^{8,24,29}$ Some of the patients in these 3 studies received bariatric surgery from the same surgeon, at the same centre, and over the same time frame as the population from 1 of the studies we included in our review. ${ }^{30}$ To avoid double counting, we included only the most comprehensive of the 4 studies. ${ }^{30}$

\section{Limitations}

One limitation of this analysis is the lack of high-quality primary studies on the topic of bariatric surgery as a treatment for IIH. Although 12 primary studies were included, the majority ${ }^{18,19,21-23,25-28,31}$ were case reports and case series. Given that case studies are particularly prone to reporting bias, the effects of bariatric surgery in the treatment of $\mathrm{IIH}$ may have been overestimated in our results.

\section{Conclusion}

Although the quality of the studies included in this systematic review was limited, bariatric surgery appears to lead to considerable improvement in the symptoms of $\mathrm{IIH}$, including headaches, visual symptoms and papilledema. Although IIH is not a well-recognized comorbidity of obesity, its presence may be considered as patients are being triaged for bariatric surgery. The presence of $\mathrm{IIH}$ in a patient with obesity may be an indication for more urgent intervention. Further research, such as randomized controlled trials and cost-benefit analyses, should be undertaken to determine the efficacy, safety and feasibility of bariatric surgery in severely obese patients with IIH.

Affiliations: From the Department of Surgery, Division of General Surgery, University of Alberta, Edmonton, Alta. (Sun, Switzer, Dang, de Gara, Birch, Karmali); the Department of Surgery, Division of General Surgery, University of Calgary, Calgary, Alta. (Gill); the Centre for the Advancement of Minimally Invasive Surgery, Royal Alexandra Hospital, Edmonton, Alta. (Shi, de Gara, Birch, Karmali); and the Division of Neurosurgery, Department of Surgery, University of Alberta, Edmonton, Alta. (Nataraj).

Competing interests: D. Birch is a consultant for Ethicon and Covidien. He has received educational grants from Ethicon, Covidien and Stryker and teaching honoraria from Cook Surgery and Bard Davol. $\mathrm{S}$. Karmali is a consultant for Gore Medical and Ethicon. No other competing interests were declared.

Contributors: W. Sun, N. Switzer, R. Gill, C. de Gara, D. Birch, A. Nataraj and S. Karmali designed the study. W. Sun and X. Shi acquired the data, which W. Sun, J. Dang, X. Shi and A. Nataraj analyzed. W. Sun, J. Dang, R. Gill and S. Karmali wrote the article, which N. Switzer, J. Dang, R. Gill, X. Shi, C. de Gara and D. Birch critically reviewed. All authors provided final approval for publication.

\section{References}

1. Wall M. Idiopathic intracranial hypertension. Neurol Clin 2010; 28:593-617.

2. Ball AK, Clarke CE. Idiopathic intracranial hypertension. Lancet Neurol 2006;5:433-42.

3. Smith JL. Whence pseudotumor cerebri? 7 Clin Neuroophthalmol 1985;5:55-6.

4. Friedman DI, Jacobson DM. Diagnostic criteria for idiopathic intracranial hypertension. Neurology 2002;59:1492-5.

5. Durcan FJ, Corbett JJ, Wall M. The incidence of pseudotumor cerebri. Population studies in Iowa and Louisiana. Arch Neurol 1988;45:875-7.

6. Radhakrishnan K, Ahlskog JE, Cross SA, et al. Idiopathic intracranial hypertension (pseudotumor cerebri). Descriptive epidemiology in Rochester, Minn, 1976 to 1990. Arch Neurol 1993;50:78-80.

7. Radhakrishnan K, Thacker AK, Bohlaga NH, et al. Epidemiology of idiopathic intracranial hypertension: a prospective and case-control study. 7 Neurol Sci 1993;116:18-28.

8. Sugerman HJ, DeMaria EJ, Felton WL III, et al. Increased intraabdominal pressure and cardiac filling pressures in obesity-associated pseudotumor cerebri. Neurology 1997;49:507-11.

9. Fridley J, Foroozan R, Sherman V, et al. Bariatric surgery for the treatment of idiopathic intracranial hypertension. 7 Neurosurg 2011;114:34-9. 
10. Handley JD, Baruah BP, Williams DM, et al. Bariatric surgery as a treatment for idiopathic intracranial hypertension: a systematic review. Surg Obes Relat Dis 2015;11:1396-403.

11. Celebisoy N, Gokcay F, Sirin H, et al. Treatment of idiopathic intracranial hypertension: topiramate vs acetazolamide, an open-label study. Acta Neurol Scand 2007;116:322-7.

12. McCarthy KD, Reed DJ. The effect of acetazolamide and furosemide on cerebrospinal fluid production and choroid plexus carbonic anhydrase activity. 7 Pharmacol Exp Ther 1974;189:194-201.

13. Johnston I, Paterson A. Benign intracranial hypertension. II. CSF pressure and circulation. Brain 1974;97:301-12.

14. Keltner JL. Optic nerve sheath decompression. How does it work? Has its time come? Arch Ophthalmol 1988;106:1365-9.

15. Bynke G, Zemack G, Bynke H, et al. Ventriculoperitoneal shunting for idiopathic intracranial hypertension. Neurology 2004; 63:1314-6.

16. Eggenberger ER, Miller NR, Vitale S. Lumboperitoneal shunt for the treatment of pseudotumor cerebri. Neurology 1996;46:1524-30.

17. Rosenberg ML, Corbett JJ, Smith C, et al. Cerebrospinal fluid diversion procedures in pseudotumor cerebri. Neurology 1993;43:1071-2.

18. Amaral JF, Tsiaris W, Morgan T, et al. Reversal of benign intracranial hypertension by surgically induced weight loss. Arch Surg 1987;122:946-9.

19. Chandra V, Dutta S, Albanese CT, et al. Clinical resolution of severely symptomatic pseudotumor cerebri after gastric bypass in an adolescent. Surg Obes Relat Dis 2007;3:198-200.

20. Egan RJ, Meredith HE, Coulston JE, et al. The effects of laparoscopic adjustable gastric banding on idiopathic intracranial hypertension. Obes Surg 2011;21:161-6.

21. Graber JJ, Racela R, Henry K. Cerebellar tonsillar herniation after weight loss in a patient with idiopathic intracranial hypertension. Headache 2010;50:146-8.

22. Leslie DB, Kellogg TA, Boutelle KN, et al. Preserved vision without growth retardation after laparoscopic Roux-en-Y gastric bypass in a morbidly obese child with pseudotumor cerebri: 36-month followup. 7 Pediatr Surg 2008;43:e27-30.

23. Levin AA, Hess D, Hohler AD. Treatment of idiopathic intracranial hypertension with gastric bypass surgery. Int 7 Neurosci 2015; 125:78-80.

24. Michaelides EM, Sismanis A, Sugerman HJ, et al. Pulsatile tinnitus in patients with morbid obesity: the effectiveness of weight reduction surgery. Am 7 Otol 2000;21:682-5.

25. Nadkarni T, Rekate HL, Wallace D. Resolution of pseudotumor cerebri after bariatric surgery for related obesity. Case report. $7 \mathrm{Neu}$ rosurg 2004;101:878-80.

26. Noggle JD, Rodning CB. Rapidly advancing pseudotumor cerebri associated with morbid obesity: an indication for gastric exclusion. South Med f 1986;79:761-3.

27. Soto FC, Antozzi P, Szomstein S, et al. Indication for emergent gastric bypass in a patient with severe idiopathic intracranial hypertension: case report and review of the literature. Surg Obes Relat Dis 2005;1:503-5.

28. Stangherlin P, Ledeghen S, Scordidis V, et al. Benign intracranial hypertension with recurrent spontaneous cerebrospinal fluid rhinorrhoea treated by laparoscopic gastric banding. Acta Chir Belg 2008;108:616-8.

29. Sugerman HJ, Felton WL III, Salvant JB Jr, et al. Effects of surgically induced weight loss on idiopathic intracranial hypertension in morbid obesity. Neurology 1995;45:1655-9.

30. Sugerman HJ, Felton WL III, Sismanis A, et al. Gastric surgery for pseudotumor cerebri associated with severe obesity. Ann Surg 1999;229:634-40, discussion 40-2.

31. Um S, Koleilat A, Dutson E, et al. Laparoscopic vertical sleeve gastrectomy for the treatment of pseudotumor cerebri. Am Surg 2013;79:E61-2.
32. NORDIC Idiopathic Intracranial Hypertension Study Group Writing Committee, Wall M, McDermott MP, et al. Effect of acetazolamide on visual function in patients with idiopathic intracranial hypertension and mild visual loss: the idiopathic intracranial hypertension treatment trial. FAMA 2014;311:1641-51.

33. Fonseca PL, Rigamonti D, Miller NR, et al. Visual outcomes of surgical intervention for pseudotumour cerebri: optic nerve sheath fenestration versus cerebrospinal fluid diversion. $\mathrm{Br} \mathcal{F}$ Ophthalmol 2014;98:1360-3.

34. Biousse V, Ameri A, Bousser MG. Isolated intracranial hypertension as the only sign of cerebral venous thrombosis. Neurology 1999; $53: 1537-42$.

35. Boulton M, Armstrong D, Flessner M, et al. Raised intracranial pressure increases CSF drainage through arachnoid villi and extracranial lymphatics. Am f Physiol 1998;275:R889-96.

36. Martins AN. Resistance to drainage of cerebrospinal fluid: clinical measurement and significance. 7 Neurol Neurosurg Psychiatry 1973;36:313-8.

37. Johnson LN, Krohel GB, Madsen RW, et al. The role of weight loss and acetazolamide in the treatment of idiopathic intracranial hypertension (pseudotumor cerebri). Opbthalmology 1998; 105:2313-7.

38. Kupersmith MJ, Gamell L, Turbin R, et al. Effects of weight loss on the course of idiopathic intracranial hypertension in women. Neurology 1998;50:1094-8.

39. Sinclair AJ, Burdon MA, Nightingale PG, et al. Low energy diet and intracranial pressure in women with idiopathic intracranial hypertension: prospective cohort study. BMF 2010;341:c2701.

40. Curioni CC, Lourenco PM. Long-term weight loss after diet and exercise: a systematic review. Int 7 Obes (Lond) 2005;29:1168-74.

41. Kirk SF, Penney TL, McHugh TL, et al. Effective weight management practice: a review of the lifestyle intervention evidence. Int $\mathcal{F}$ Obes (Lond) 2012;36:178-85.

42. Miller WC, Koceja DM, Hamilton EJ. A meta-analysis of the past 25 years of weight loss research using diet, exercise or diet plus exercise intervention. Int 7 Obes Relat Metab Disord 1997;21:941-7.

43. Wu T, Gao X, Chen M, et al. Long-term effectiveness of diet-plusexercise interventions vs. diet-only interventions for weight loss: a meta-analysis. Obes Rev 2009;10:313-23.

44. Carlin AM, Zeni TM, English WJ, et al. The comparative effectiveness of sleeve gastrectomy, gastric bypass, and adjustable gastric banding procedures for the treatment of morbid obesity. Ann Surg 2013;257:791-7.

45. Chang SH, Stoll CR, Song J, et al. The effectiveness and risks of bariatric surgery: an updated systematic review and meta-analysis, 20032012. 7AMA Surg 2014;149:275-87.

46. Gloy VL, Briel M, Bhatt DL, et al. Bariatric surgery versus nonsurgical treatment for obesity: a systematic review and meta-analysis of randomised controlled trials. BMF 2013;347:f5934.

47. Christou N, Efthimiou E. Five-year outcomes of laparoscopic adjustable gastric banding and laparoscopic Roux-en-Y gastric bypass in a comprehensive bariatric surgery program in Canada. Can 7 Surg 2009;52:E249-58.

48. Tice JA, Karliner L, Walsh J, et al. Gastric banding or bypass? A systematic review comparing the two most popular bariatric procedures. Am 7 Med 2008;121:885-93.

49. Wall M, George D. Idiopathic intracranial hypertension. A prospective study of 50 patients. Brain 1991;114(Pt 1A):155-80.

50. Thambisetty M, Lavin PJ, Newman NJ, et al. Fulminant idiopathic intracranial hypertension. Neurology 2007;68:229-32.

51. Buchwald H, Oien DM. Metabolic/bariatric surgery worldwide 2011. Obes Surg 2013;23:427-36.

52. Padwal RS, Chang HJ, Klarenbach S, et al. Characteristics of the population eligible for and receiving publicly funded bariatric surgery in Canada. Int 7 Equity Health 2012;11:54. 